\title{
The Severity of Growth Hormone Deficiency Does Not Predict the Presence or Absence of Brain Magnetic Resonance Imaging Abnormalities - A Retrospective Review
}

\author{
Patria Alba, ${ }^{1}$ Sarah Tsai $^{2}$ and Naim Mitre $^{2}$ \\ 1. Department of Pediatric Endocrinology, Blank Children's Hospital, Des Moines, IA, USA; 2. Department of Endocrinology, Children's Mercy Hospital, \\ University of Missouri-Kansas City (UMKC), Kansas City, MO, USA
}

DOI: $h$ ttps://doi.org/10.17925/EE.2020.16.1.60

$\mathrm{B}$ ackground: The Growth Hormone Research Society recommends that all patients diagnosed with growth hormone deficiency (GHD) should undergo brain magnetic resonance imaging (MRI). This is still a point of controversy in patients with mild GHD, as the level of peak growth-hormone (GH) as a predictor of brain MRI abnormality has not yet been established. The objective of this study was to determine if peak GH level, determined by stimulation tests, can predict the presence or absence of brain MRI abnormality. Methods: This study was a retrospective chart review from 2008-2015. Patients were aged 2-18 years, and had growth failure and GHD as determined by stimulation test. Patients with history of brain tumour, chemotherapy and brain surgery, prior to the diagnosis of GHD, were excluded. Results: A total of 386 patients were included. GH values (mild versus severe GHD) did not predict brain MRI abnormality with any agent (clonidine: $\mathrm{p}=0.07$; arginine: $\mathrm{p}=0.17$; glucagon: $\mathrm{p}=0.42$ ). Abnormal MRI was apparent in $19.2 \%$ of the patients with mild GHD and $24.8 \%$ of the patients with severe GHD ( $\mathrm{p}=0.17)$. Severe MRI abnormality was seen in $6.1 \%$ of the patients with mild $\mathrm{GHD}$ and $15.0 \%$ of the patients with severe GHD ( $p=0.009)$. Conclusions: The severity of GHD based on peak $\mathrm{GH}$ levels on stimulation tests did not predict the presence or absence of brain MRI abnormalities in our study population; however, severe GHD was more strongly associated with severe brain MRI abnormalities. Based on these results we recommend obtaining brain MRI in all patients with GHD.

\section{Keywords}

Growth hormone deficiency,

stimulation test, brain MRI abnormality

Disclosures: Naim Mitre, Sarah Tsai and Patria Alba have no financial or non-financial relationships or activities to declare in relation to this article.

Acknowledgments: The authors would like to thank Dr Neil Mardis and Dr Timothy Zinkus for reviewing the brain magnetic resonance images

Review Process: Double-blind peer review.

Compliance with Ethics: This article involves a retrospective chart review and does not report on new clinical data, or any studies with human or animal subjects performed by any of the

authors. The research protocol was approved by the Institutional Review Board. Informed consent was waived because of less than minimal risk.

Authorship: All named authors meet the criteria of the International Committee of Medical Journal Editors for authorship for this manuscript, take responsibility for the integrity of the work as a whole and have given final approval for the version to be published. Access: This article is freely accessible at touchENDOCRINOLOGY.com (C) Touch Medical Media 2020 Received: 1 August 2019

Accepted: 3 October 2019

Published Online: 5 February 2020

Citation: European Endocrinology. 2020;16(1):60-4 Corresponding Author: Patria Alba, Department of Pediatric Endocrinology, Blank Children's Hospital, 1215 Pleasant Street, Suite 300, Des Moines, IA 50309, USA. E: patria_alba@hotmail.com

Support: No funding was received in

the publication of this article.
Growth hormone deficiency (GHD) is an endocrine cause of short stature. GHD may be idiopathic, due to brain tumours affecting the pituitary gland, morphologic pituitary abnormalities, or genetic defects. ${ }^{1,2}$ The diagnosis of GHD is based on auxologic criteria and laboratory studies including tests of growth hormone (GH) secretion by stimulating $\mathrm{GH}$ release. ${ }^{3}$ The identification of central nervous system (CNS) tumours remains the primary purpose of neuroradiological imaging in the evaluation of children with GHD, but brain magnetic resonance imaging (MRI) also has a secondary role identifying abnormalities in the pituitary anatomy that aid the clinician in the diagnosis and prognosis. $2 ., 45$

The Growth Hormone Research Society currently recommends that an MRI of the brain, with particular attention to the hypothalamic-pituitary region, should be carried out in any child diagnosed with GHD. ${ }^{3}$ However, there is no clear evidence to support these recommendations in patients with mild GHD (peak stimulated GH value between 5 and $<10 \mathrm{ng} / \mathrm{mL}$ ). ${ }^{6}$ The prevalence of pituitary abnormalities and brain tumours seems to be higher in patients with lower $\mathrm{GH}$ values in provocative testing. However, peak GH value as predictor of the presence or absence of brain MRI abnormalities has not yet been clearly defined.

Previous studies have been inconclusive, showing a wide variability in the prevalence of MRI abnormalities in patients with GHD, ranging from $25.9-100.0 \% .^{8-12}$ Due to this variability patients with mild GH values (peak stimulated GH value between 5 and $<10 \mathrm{ng} / \mathrm{mL}$ ) are unlikely to undergo a brain MRI. This is evidenced by the fact that in the clinical settings some healthcare providers will only obtain brain MRI if the patient has severe GHD (GH level $<5 \mathrm{ng} / \mathrm{mL}$ ) or if there are other risk factors present (such as other pituitary hormone deficiencies, severe headache, vision problems). Therefore, despite the recommendations from the Growth Hormone Research Society, when to obtain a brain MRI in patients with GHD remains controversial. ${ }^{8-12}$

The aim of this study was to evaluate peak GH levels, determined by provocative testing, as a predictor of the presence or absence of brain MRI abnormalities and to determine if a brain MRI should be performed in all patients with GHD. A secondary aim was to identify whether symptoms suggestive of brain abnormalities influenced this prediction. 


\section{Methods}

\section{Study population}

This retrospective study included all paediatric patients diagnosed with GHD at a tertiary paediatric referral center, Children's Mercy Hospital, Kansas City, MO, USA, from January 2008 to January 2015. The Institutional Review Board approved the research protocol. Informed consent was waived because of less than minimal risk. The conducted research is not related to either human or animal use. Chart reviews were based on International Classification of Diseases, Ninth Revision, Clinical Modification (ICD-9-CM) codes: 253.3 (GHD), 259.4 (dwarfism), 781.91 (loss of height), 783.41 (failure to thrive), and 783.43 (short stature). The diagnosis of GHD was based on growth failure and peak $\mathrm{GH}$ level on stimulation test of $<10 \mathrm{ng} / \mathrm{mL}$ with two stimulants (either clonidine, arginine and/or glucagon). All patients with GHD underwent brain MRI with detailed examination of the hypothalamic-pituitary area at diagnosis.

Patients with GHD that did not have a brain MRI after the diagnosis of GHD was made were excluded from the study. Patients with known CNS anatomical abnormalities, history of cranial radiation and history of CNS trauma before the diagnosis of GHD were also excluded from the study. These particular exclusion criteria were applied as these parameters represent acquired causes of pituitary dysfunction in which GHD was expected to develop, and in which GHD was diagnosed after MRI and the lesion was treated.

\section{Diagnosis of growth hormone deficiency}

Prior to inclusion in this chart review, standing height was measured with a Harpenden stadiometer (QuickMedical, Issaquah, WA, USA). Height was calculated using the World Health Organization (WHO) child growth standards. ${ }^{3}$ Height velocity was calculated using Tanner's growth charts. ${ }^{3}$ The following clinical and auxological assessment were considered characteristics of growth failure: height $>3.0$ standard deviation score (SDS) below the mean; height >1.5 SDS below the mid-parental height; height $>2.0$ SDS below the mean with a height velocity over 1 year >1.0 SDS below the mean for chronological age; or a decrease in height SDS of $>0.5$ over 1 year in children $>2$ years of age. In the absence of short stature, a height velocity $>2.0$ SDS below the mean over 1 year or $>1.5$ SDS sustained over 2 years. ${ }^{3}$ Chronic diseases, malnutrition and other endocrine disorders were excluded as the cause of the short stature.

The diagnosis of GHD was based on growth failure and peak GH levels of $<10 \mathrm{ng} / \mathrm{mL}$ in GH stimulation test with two stimulants. GHD was divided in to mild (peak GH level between 5-10 ng/mL) and severe (peak GH level $<5 \mathrm{ng} / \mathrm{mL}$ ). ${ }^{6}$ In patients that failed the $\mathrm{GH}$ stimulation test with one stimulant, but passed with a second stimulant and there was strong suspicion of GHD, a third stimulant was used. If these patients failed with two stimulants, they were included in the study. The stimulants used were clonidine, arginine and glucagon. Stimulants were administered with the following doses: clonidine $0.1 \mathrm{mg} / \mathrm{m}^{2}$, oral; arginine $0.5 \mathrm{gm} / \mathrm{kg}$, administered intravenously over 30 minutes; and glucagon $0.03 \mathrm{mg} / \mathrm{kg}$, subcutaneous. GH levels were measured at 0, 30, 60, 90, 120, 150 and 180 minutes after the administration of stimulants.

All patients with diagnosis of GHD underwent a brain MRI, performing pre- and post-gadolinium per radiologist discretion, with enhanced T1- and T2-weighted images in axial, coronal and sagittal sections. All the scans were evaluated by the same method by one observer, and were later validated by two different blinded radiologists, and the consensus achieved. The size and signal intensities of the anterior pituitary were evaluated.
Pituitary gland height was measured in a plane perpendicular to the floor of the sella turcica to the highest point of the superior gland surface, usually at the point of insertion of the pituitary stalk. Pituitary hypoplasia was defined as a pituitary height SDS $<-2$. The pituitary stalk was classified as normal, thick, thin (hypoplastic), truncated or absent. The stalk was defined as hypoplastic if there was a significant reduction at any level in its diameter or irregularity along its length, but it remained in continuity with the pituitary. The neurohypophyisis was defined as normal or ectopically placed. Ectopia was diagnosed on the basis of absence of the normal posterior lobe high signal on T1 sequences in the sella turcica, and the presence of high signal in the infundibular recess of the third ventricle. ${ }^{3-5,7,9}$

\section{Classification of brain abnormalities on magnetic resonance imaging}

Brain MRI was classified as normal versus abnormal, depending on whether CNS anatomy was disrupted or not. If CNS anatomy was disrupted, this was further classified as associated versus not associated with pituitary gland. When associated with the pituitary gland, documentation was provided regarding pituitary hypoplasia/aplasia, anatomy of the stalk, and position of the posterior pituitary. Brain MRI abnormalities were divided in mild and severe. Mild abnormalities were classified as ones that were less likely associated with pituitary hormone deficiencies, and severe abnormalities were classified as those that are more likely associated with pituitary hormone deficiencies. ${ }^{24,8,9}$

Signs/symptoms suggestive of intracranial pathology included headache, vision problems (blurred vision, double vision, loss of peripheral vision), symptoms of pituitary hormone deficiency, central hypothyroidism, central diabetes insipidus, central adrenal insufficiency and hypogonadotropic hypogonadism.

\section{Statistical analysis}

Comparisons were made based on gender (male versus female), age (2-4 years, 5-9 years, 10-14 years and 15-18 years), peak GH value on GH stimulation test (mild versus severe GHD) and brain MRI results (normal versus abnormal, and mild versus severe abnormality). The comparison between groups was evaluated using independent samples t-test, Chi-square and Fisher's exact test. These data are presented as mean \pm SDS. Statistical significance was determined with an alpha of $p<0.05$. The analysis was done using SAS (version 9.4; SAS Institute Inc., Cary, NC, USA) and SPSS (version 22.0; SPSS Institute, Chicago, IL, USA).

\section{Results}

Six hundred and twenty-eight charts were reviewed, and a total of 386 patients with GHD that underwent brain MRI were included in the study. Two hundred and ninety patients were male $(75.1 \%)$ and 96 patients were female (24.9\%). Age of patients ranged from 2-18 years old.

Of the 386 patients, 300 patients had a normal brain MRI (77.7\%) and 86 patients had an abnormal brain MRI (22.3\%). There was no difference in the prevalence of abnormal MRI between male and female patients (21.3\% of males and $25.0 \%$ of females had an abnormal brain MRl; $\mathrm{p}=0.45$ ). Brain MRI abnormalities were more prevalent between 2-9 years old (Table 1).

Of the 213 patients with mild GHD, 170 had a normal brain MRI (79.8\%), 30 had mild brain MRI abnormality (14.1\%) and 13 had severe brain MRI abnormality (6.1\%). Of the 173 patients with severe GHD, 130 had a normal brain MRI (75.1\%), 17 had mild brain MRI abnormality (9.8\%) 
Table 1: Brain magnetic resonance imaging outcomes according to the different age groups

\begin{tabular}{|l|l|l|l|}
\hline \multirow{2}{*}{ Age (years) } & \multicolumn{2}{|l|}{ Brain MRI outcomes } & Total \\
\cline { 2 - 3 } & Normal $(n=300)$ & Abnormal $(n=86)$ & \\
\hline $2-4$ & $8(47.0 \%)$ & $9(52.9 \%)$ & 17 \\
\hline $5-9$ & $55(67.9 \%)$ & $26(32.1 \%)$ & 81 \\
\hline $10-14$ & $208(82.5 \%)$ & $44(17.5 \%)$ & 252 \\
\hline $15-18$ & $29(80.5 \%)$ & $7(19.5 \%)$ & 36 \\
\hline
\end{tabular}

$M R I=$ magnetic resonance imaging .

Table 2: Severity of growth hormone deficiency versus severity of brain abnormalities on magnetic resonance imaging

\begin{tabular}{|l|l|l|l|l|l|}
\hline GHD & \multicolumn{2}{|l|}{ MRI finding } & \multicolumn{3}{l|}{ P value } \\
& $\begin{array}{l}\text { Normal } \\
(n=300)\end{array}$ & $\begin{array}{l}\text { Mild } \\
(n=47)\end{array}$ & $\begin{array}{l}\text { Severe } \\
(n=39)\end{array}$ & $\begin{array}{l}\text { Normal versus } \\
\text { abnormal } \\
\text { MRI }\end{array}$ & $\begin{array}{l}\text { Mild versus } \\
\text { severe MRI } \\
\text { abnormality }\end{array}$ \\
\hline $\begin{array}{l}\text { Mild } \\
(n=213)\end{array}$ & $170(79.8 \%)$ & $30(14.1 \%)$ & $13(6.1 \%)$ & 0.17 & 0.009 \\
\hline $\begin{array}{l}\text { Severe } \\
(n=173)\end{array}$ & $130(75.1 \%)$ & $17(9.8 \%)$ & $26(15.0 \%)$ & & \\
\hline
\end{tabular}

*Abnormal MRI includes both mild and severe abnormalities.

Brain MRI findings (normal versus mild abnormality and mild abnormality versus severe abnormality) in mild GHD and severe GHD.

$G H D=$ growth hormone deficiency; $M R I=$ magnetic resonance imaging .

and 26 had severe brain MRI abnormality (15.0\%) (Table 2). There was no difference in prevalence of MRI abnormalities between patients with mild GHD and severe GHD ( $p=0.17)$. Severe brain MRI abnormalities were more prevalent in patients with severe GHD compared to mild GHD $(p=0.009)$. The distribution of brain MRI findings according to severity of GHD is depicted in Table 3.

The difference in peak GH values was not statistically significant for patients with normal versus abnormal MRI, with any agent (clonidine: $p=0.07$; arginine: $p=0.17$; glucagon: $p=0.42$ ) (Table 4 and Figure 1). The presence of signs/symptoms concerning for CNS disease was predictive of MRI abnormality (55.0\% of symptomatic patients had an abnormal MRl; $p<0.001$ ) (Table 5). Controlling for symptoms did not provide statistical significance when comparing the mild GHD versus the severe GHD groups. In the absence of symptoms, $81.9 \%$ of the patients with mild GHD had a normal MRI and $80.1 \%$ of the patients with severe GHD had a normal MRI $(p=0.80)$. In the presence of symptoms, $37.0 \%$ of the patients with mild GHD versus $49.0 \%$ of the patients with severe GHD had an abnormal MRI $(\mathrm{p}=0.4)$.

\section{Discussion}

The results in our study population show that peak stimulated GH levels did not predict the presence or absence of brain MRI abnormalities. The prevalence of severe brain MRI abnormalities was higher in patients with severe GHD, but patients with mild GHD also had severe brain MRI abnormalities that are considered clinically significant. Even when controlling for symptoms and signs of CNS disease, there was no difference in prevalence of brain MRI abnormalities between patients with mild versus severe GHD. Previous studies have shown discrepant results regarding the prevalence of brain MRI abnormalities in patients with GHD and therefore recommendations as to when to obtain a brain MRI in these patients remains controversial.
Table 3: Distribution of magnetic resonance imaging findings at diagnosis in relation to growth hormone deficiency severity

\begin{tabular}{|l|l|l|l|l|l|}
\hline \multicolumn{2}{|c|}{ Mild brain MRI abnormality } & \multicolumn{5}{l|}{ Severe brain MRI abnormality } \\
& $\begin{array}{l}\text { GHD } \\
(\mathrm{n}=30)\end{array}$ & $\begin{array}{l}\text { Severe } \\
\text { GHD } \\
(\mathrm{n}=17)\end{array}$ & $\begin{array}{l}\text { Mild } \\
\text { GHD } \\
(\mathrm{n}=13)\end{array}$ & $\begin{array}{l}\text { Severe } \\
\text { GHD } \\
(\mathrm{n}=26)\end{array}$ \\
\hline $\begin{array}{l}\text { Pars } \\
\text { intermedia cyst }\end{array}$ & 8 & 5 & $\begin{array}{l}\text { Empty sella/partial } \\
\text { empty sella }\end{array}$ & 3 & 4 \\
\hline Microadenoma & 2 & 0 & $\begin{array}{l}\text { Ectopic posterior } \\
\text { pituitary }\end{array}$ & 4 & 13 \\
\hline Gliosis & 10 & 6 & $\begin{array}{l}\text { Hamartoma and } \\
\text { craniopharyngioma }\end{array}$ & 2 & 2 \\
\hline $\begin{array}{l}\text { Cerebellar } \\
\text { ectopia }\end{array}$ & 9 & 5 & $\begin{array}{l}\text { Thickened } \\
\text { infundibulum }\end{array}$ & 1 & 1 \\
\hline $\begin{array}{l}\text { Absent septum } \\
\text { pellucidum }\end{array}$ & 1 & 1 & $\begin{array}{l}\text { Anterior pituitary } \\
\text { hypoplasia }\end{array}$ & 2 & 4 \\
\hline Optic nerve & 1 & 2 \\
\hline
\end{tabular}

GHD = growth hormone deficiency; MRI = magnetic resonance imaging.

Table 4: Peak growth hormone values (ng/mL) for each stimulant

\begin{tabular}{|l|l|l|l|l|l|}
\hline Stimulant & Mean & SD & Median & Minimum & Maximum \\
\hline Clonidine $(n=375)$ & 4.39 & 2.98 & 4.10 & 0.10 & 13.90 \\
\hline Arginine $(n=375)$ & 4.23 & 2.65 & 3.80 & 0.10 & 16.00 \\
\hline Glucagon $(n=43)$ & 7.07 & 5.02 & 6.50 & 0.40 & 22.10 \\
\hline
\end{tabular}

SD $=$ standard deviation.

Tillmann et al. investigated the relationship between pituitary appearance and the diagnosis of GHD. They assessed MRI scans along with GH status on stimulation tests in 110 patients. GHD was established with a peak GH level of $<5.8 \mathrm{ng} / \mathrm{mL}$, a lower cut off than the one used in our study. In Tillmann's study, $79.2 \%$ of patients with GHD had hypothalamic-pituitary axis abnormality, which is much higher than in the population presented here. Even when comparing patients with severe GHD and severe brain MRI abnormalities, the prevalence in our study was $15.0 \%$, compared to a prevalence of $54 \%$ in the study of Tillmann et al. They also found that $46 \%$ of patients that were $\mathrm{GH}$ sufficient (GH level $>5.8 \mathrm{ng} / \mathrm{mL}$ ) had a brain MRI abnormality. They recommended obtaining brain MRI in all patients with GHD as an aid to diagnosis. ${ }^{13}$

Acharya et al..$^{14}$ and Maghnie et al. ${ }^{15}$ had different findings from Tillmann's study and showed that all patients with pituitary abnormalities had a peak GH level, determined by stimulation tests, of $<3 \mathrm{ng} / \mathrm{mL}$ (prevalence 53\%). These results suggest that only patients with peak $\mathrm{GH}$ level of $<3 \mathrm{ng} / \mathrm{mL}$ should undergo brain MRI. Another study from Maghnie et al. showed similar results, with data suggesting that GHD is more severe in patients with ectopic posterior pituitary, indicating that an abnormal brain MRI is highly predictive of severe GHD. ${ }^{16}$ Based on these studies, brain MRI can contribute to the prediction of the pattern and severity of GHD. ${ }^{14}$

Lo et al. found no significant clinical difference in the severity of brain MRI abnormalities in patients with severe GHD and mild GHD. In the severe GHD group there were $23 \%$ of patients with pituitary hypoplasia, compared to $11 \%$ in the mild GHD group. They also found one interrupted 
Figure 1: Distribution of peak growth hormone level on stimulation tests with clonidine (A), arginine (B) and glucagon $(C)$ correlated with brain magnetic resonance imaging finding

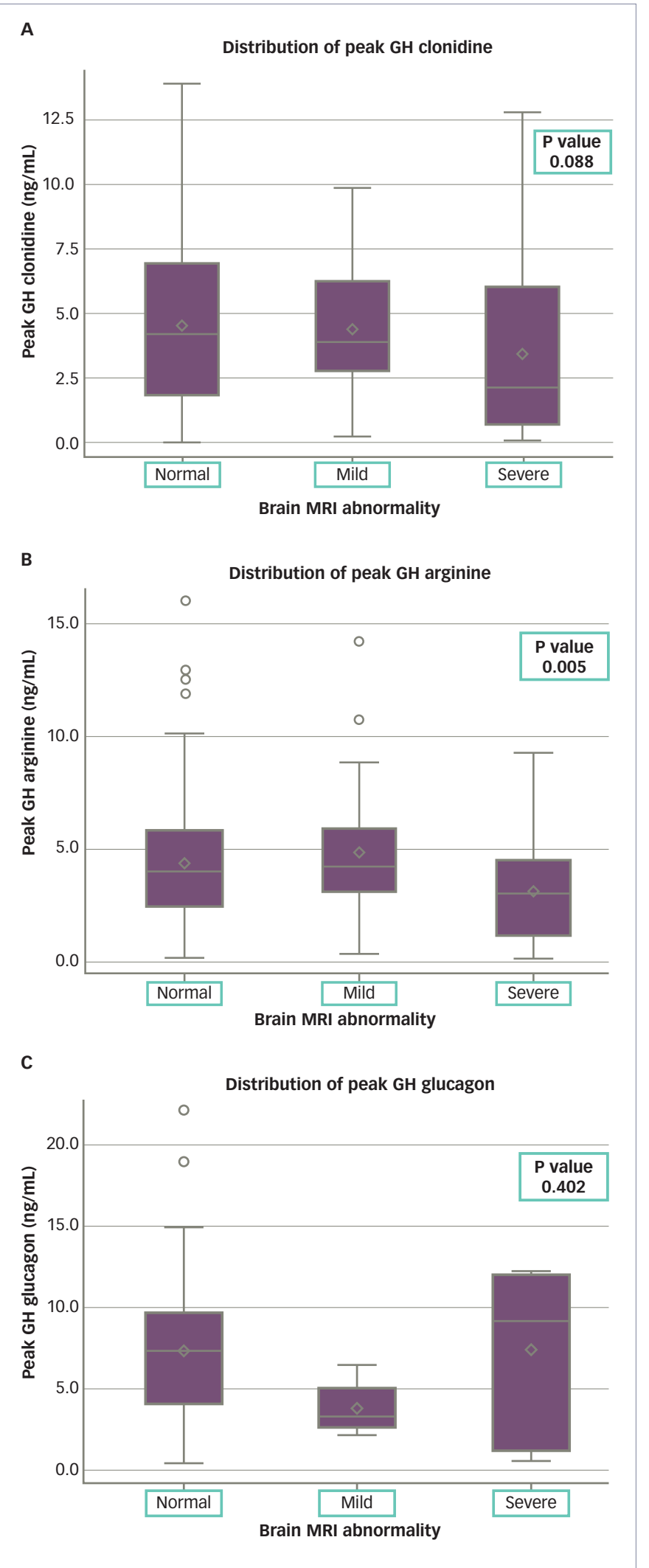

Peak GH level on stimulation tests with clonidine, arginine and glucagon did not predict brain MRI findings.

$\mathrm{GH}=$ growth hormone; $M R I=$ magnetic resonance imaging.
Table 5: Signs/symptoms of central nervous system disease and brain magnetic resonance imaging finding

\begin{tabular}{|l|l|l|l|}
\hline Symptoms & Normal MRI & Abnormal MRI & P value \\
\hline Absent & $269(81.5 \%)$ & $61(18.5 \%)$ & $<0.001$ \\
\hline Present & $25(44.6 \%)$ & $31(55.4 \%)$ & \\
\hline
\end{tabular}

MRI = magnetic resonance imaging.

stalk and one ectopic posterior pituitary in the severe GHD group, but none in the mild GHD group. As there were no significant differences between these groups, it was recommended to obtain a brain MRI in all patients with GHD. ${ }^{17}$ This outcome is similar to our results, showing no difference in the prevalence of brain MRI abnormalities in patients with mild versus severe GHD (patients with severe GHD had a prevalence of brain MRI abnormalities of $24.9 \%$, compared to $20.2 \%$ for the patients with mild GHD; $p=0.17$ ).

Another study, from Canada, showed a high prevalence of brain MRI abnormalities in patients with GHD (80\%). The higher prevalence of MRI abnormalities is likely due to the more stringent criteria used to diagnose GHD in this institution, including peak GH level of $<8 \mathrm{ng} / \mathrm{mL}$ on three tests - two pharmacologic and one physiological. ${ }^{18}$ These criteria are different from the ones used in our study which likely explains the difference in prevalence. Their data suggest that brain MRI should be done in all patients with GHD, but it is not clear if the prevalence of brain MRI abnormality is inversely proportional to the peak GH level on stimulation test.

Rosenfeld et al. investigated which patients with GHD are most likely to benefit from MRI. Their study included 100 patients who failed $\mathrm{GH}$ screening tests. ${ }^{6}$ They found a significant relationship between the presence of risk factors, maximal $\mathrm{GH}$ level of $<5 \mathrm{ng} / \mathrm{mL}$, and sellar defects. With no risk factors, MRI scans showed normal findings in 15 of 17 patients with maximal $\mathrm{GH}$ of $<5 \mathrm{ng} / \mathrm{mL}$, in 33 of 34 patients with $\mathrm{GH}$ between $5-10 \mathrm{ng} / \mathrm{mL}$, and in all 35 patients with $\mathrm{GH}$ of $>10 \mathrm{ng} / \mathrm{mL}$. They concluded that MRI scans should be obtained in any child with risk factors (such as multiple pituitary hormone deficiency, hypoglycaemia, ophthalmologic anomalies, low-stimulated $\mathrm{GH}$ or acquired growth failure). Otherwise, asymptomatic children with growth delay and maximal $\mathrm{GH}$ of $>10 \mathrm{ng} / \mathrm{mL}$ do not need routine MRI screening. Patients with mild GHD and risk factors should undergo an MRI. Patients with mild GHD and no risk factors, are unlikely to benefit from MRI. ${ }^{6}$ Our results are similar to those of Rosenfeld et al., as we found that symptoms of CNS disease are predictive of brain MRI abnormality ( $55 \%$ of symptomatic patients had an abnormal MRl; $p<0.001$ ) (Table 5). However, in our population, the prevalence of MRI abnormalities was similar in the mild and severe GHD groups, independently of the symptoms, which differs from Rosenfeld's recommendations regarding obtaining brain MRI in patients with mild GHD only if they are having symptoms concerning of CNS disease.

In our study, $77.7 \%$ of patients with GHD had a normal brain MRI. This is similar to other studies that have found that a normal MRI is the most common finding in children with GHD. ${ }^{19,20}$ As with our study, the abnormalities found in other studies include empty sella/partial empty sella, posterior pituitary ectopy, decreased pituitary size, thickened infundibulum, optic nerve hypoplasia and tumours like hamartoma and craniopharyngioma. ${ }^{2,47,7,19,21,22}$ 
One of the limitations of this study is that the analysis was not confined to $\mathrm{GH}$ levels of $<10 \mathrm{ng} / \mathrm{mL}$. Our data show some $\mathrm{GH}$ levels of $>10 \mathrm{ng} / \mathrm{mL}$ as a result of patients who failed a GH stimulation test with one stimulant but passed with a second stimulant, in which case, if there was strong suspicion of GHD, a third stimulant was used. However, this serves to show that $\mathrm{GH}$ levels on stimulation tests are not a good predictor of brain MRI abnormalities.

\section{Conclusion}

Based on conflicting findings in previous research studies, the topic of conducting brain MRI on all paediatric patients with GHD remains controversial. The identification of CNS tumours remains the primary purpose of neuroradiological imaging in the evaluation of children with GHD but brain MRI also has a secondary role identifying abnormalities in the pituitary anatomy such as irregularities in pituitary size, location and stalk connection. These structural abnormalities help validate the diagnosis of GHD. Finding structural abnormalities also aids in the prognosis and follow-up of patients as they have higher risk of developing other pituitary hormone deficiencies and adult GHD.,2,12

The Growth Hormone Research Society published a consensus guideline for the diagnosis and treatment of GHD in paediatric patients in 2000. They recommended that an MRI of the brain with particular attention to the hypothalamic-pituitary region should be carried out in any child diagnosed with GHD. ${ }^{3}$ Until the present study, there was no clear evidence to support these recommendations. Previous series have reported an incidence of MRI abnormalities between 25.9-100.0\% in patients with GHD.8-10,12

With the discrepancy of the results in previous studies, some investigators have advocated MRI studies for any patient with GHD, 13,17,18 while others recommend imaging studies after confirmation of a severe defect in $\mathrm{GH}$ secretion, ${ }^{6,14-6}$ or after clinical and biochemical data suggests intracranial pathology.

Our results show that the severity of GHD based on peak GH levels determined by stimulation tests did not predict the presence or absence of MRI abnormalities in our study population. The prevalence of severe brain MRI abnormalities was higher in patients with severe GHD, but patients with mild GHD also had severe brain MRI abnormalities that are considered clinically significant. Even when controlling for symptoms and signs of CNS disease, there was no difference in prevalence of brain MRI abnormalities between patients with mild versus severe GHD. In conclusion, based on these results we recommend obtaining brain MRI in all patients with clinical and axiological data suggestive of GHD regardless of the peak $\mathrm{GH}$ level on stimulation test. $]$
1. Triulzi F, Scotti G, di Natale B, et al. Evidence of a congenital midline brain anomaly in pituitary dwarfs: a magnetic resonance imaging study in 101 patients. Pediatrics. 1994;93:409-16.

2. Jagtap VS, Acharya SV, Sarathi V, et al. Ectopic posterior pituitary and stalk abnormality predicts severity and coexisting hormone deficiencies in patients with congenital growth hormone deficiency Pituitary. 2012;15:243-50

3. Growth Hormone Research Society. Consensus guidelines for the diagnosis and treatment of growth hormone (GH) deficiency in childhood and adolescence: summar (GH) deficiency in childhood and adolescence: summary
statement of the GH Research Society. GH Research Society. statement of the GH Research Society. GH

4. Arslanoglu I, Kutlu H, Isguven P, et al. Diagnostic value of pituitary MRI in differentiation of children with normal growth hormone secretion, isolated growth hormone deficiency an multiple pituitary hormone deficiency. J Pediatr Endocrinol Metab. 2001;14:517-23.

5. Abernethy $\downarrow$. Imaging of the pituitary in children with growth disorders. Eur J Radiol. 1998;26:102-8.

6. Rosenfeld RG, Albertsson-Wikland K, Cassorla F, et al. Diagnostic controversy: the diagnosis of childhood growth hormone deficiency revisited. I Clin Endocrinol Metab. 1995;80:1532-40

7. Frindik JP, Kemp SF, Pihoker C. Effective use of magnetic resonance imaging in the assessment of children with possible growth hormone deficiency. Endocr Pract. 1996;2:8-12.
8. Meszaros F, Vergesslich K, Riedl S, et al. Posterior pituitary ectopy in children with idiopathic growth hormone deficiency. J Pediatr Endocrinol Metab. 2000;13:629-35.

9. Bressani N, di Natale B, Pellini C, et al. Evidence of morphological and functional abnormalities in the hypothalamus of growth-hormone-deficient children: a combined magnetic resonance imaging and endocrine study. Horm Res. 1990;34:189-92

10. Arends NJ, V d Lip W Robben SG, Hokken-Koelega AC. MRI findings of the pituitary gland in short children born small for gestational age (SGA) in comparison with growth hormone-deficient (GHD) children and children with normal hormone-deficient (GHD) Children and children wing
stature. Clin Endocrinol (Oxf). 2002:57:719-24.

11. Kornreich L, Horev G, Lazar L, et al. MR findings in hereditary isolated growth hormone deficiency. AJNR Am I Neuroradid. 1997;18:1743-7.

12. Kalina MA, Kalina-Faska B, Gruszczynska K, et al. Usefulness of magnetic resonance findings of the hypothalamic-pituitary region in the management of short children with growth hormone deficiency: evidence from a longitudinal study. Childs Nerv Syst. 2012;28:121-7.

13. Tillmann $\mathrm{V}$, Tang VW, Price $\mathrm{DA}$, et al. Magnetic resonance imaging of the hypothalamic-pituitary axis in the diagnosis of growth hormone deficiency I Pediatr Endocrinol Metab. 2000;13:1577-83.

14. Acharya SV, Gopal RA, Lila A, et al. Phenotype and radiological correlation in patients with growth hormone deficiency. Indian J Pediatr. 2011:78:49-54.
15. Maghnie M, Loche S, Cappa M. Pituitary magnetic resonance imaging in idiopathic and genetic growth hormone deficiency. J Clin Endocrinol Metab. 2003;88:1911.

16. Maghnie M, Villa A, Arico M, et al. Correlation between magnetic resonance imaging of posterior pituitary and neurohypophyseal function in children with diabetes insipidus. J Clin Endocrinol Metab. 1992;74:795-800.

17. LO FS, Chang LY, Yang MH, et al. Auxological, clinical and MRI findings in Taiwanese children with growth hormone deficiency. I Pediatr Endocrinol Metab. 2004:17:1519-26.

18. Hamilton J, Blaser S, Daneman D. MR imaging in idiopathic growth hormone deficiency. AJNR Am J Neuroradiol. 1998;19:1609-15.

19. Tsai SL, Laffan E, Lawrence S. A retrospective review of pituitary MRI findings in children on growth hormone therapy. Pediatr Radiol. 2012;42:799-804

20. Maghnie M, Lindberg A, Koltowska-Haggstrom M, Ranke MB Magnetic resonance imaging of CNS in 15,043 children with GH deficiency in KIGS (Pfizer International Growth Database). Eur J Endocrinol. 2013;168:211-7.

21. Chen S, Leger J, Garel C, et al. Growth hormone deficiency with ectopic neurohypophysis: anatomical variations and relationship between the visibility of the pituitary stalk asserted by magnetic resonance imaging and anterior pituitary function. Clin Endocrinol Metab. 1999:84:2408-13. pituitary function.J Clin Endocrinol Metab. 1999;84:2408-13,

the hypothalamic-pituitary area in idiopathic growth deficiency. chin Med Sci J. 1997:12:121-5. 